\title{
Mechanical, Thermal, and Barrier Properties of Methylcellulose/Cellulose Nanocrystals Nanocomposites
}

\author{
Hudson Alves Silvério, Wilson Pires Flauzino Neto, Ingrid Souza Vieira da Silva, \\ Joyce Rover Rosa, Daniel Pasquini \\ Instituto de Química, Universidade Federal de Uberlândia - UFU \\ Rosana Maria Nascimento de Assuncão \\ Faculdade de Ciências Integradas do Pontal, Universidade Federal de Uberlândia - UFU \\ Hernane da Silva Barud, Sidney José Lima Ribeiro \\ Instituto de Química de Araraquara, Universidade Estadual Paulista Júlio de Mesquita - UNESP

\begin{abstract}
In this work, the effects of incorporating cellulose nanocrystals from soy hulls $\left(\mathrm{WSH}_{30}\right)$ on the mechanical, thermal, and barrier properties of methylcellulose $(\mathrm{MC})$ nanocomposites were evaluated. $\mathrm{MC} / \mathrm{WSH}_{30}$ nanocomposite films with different filler levels $(2,4,6,8$, and $10 \%)$ were prepared by casting. Compared to neat MC film, improvements in the mechanical and barrier properties were observed, while thermal stability was retained. The improved mechanical properties of nanocomposites prepared may be attributed to mechanical percolation of $\mathrm{WSH}_{30}$, formation of a continuous network of $\mathrm{WSH}_{30}$ linked by hydrogen interactions and a close association between filler and matrix.
\end{abstract}

Keywords: Cellulose nanocrystals, agro-industrial residue, reinforcement, methylcellulose, nanocomposites.

\section{Introduction}

Synthetic oil-based polymers are widely used as packaging because of their excellent properties, including high strength, elongation, lightweight, and water resistance. These plastics are convenient, safe, strong, and economical (inexpensive), but not biodegradables ${ }^{[1]}$. Therefore, several groups have tried to develop packaging from renewable sources that are environmentally friendly, inexpensive, lightweight, possess good thermomechanical properties, and provide a reasonable barrier to the transfer of liquids and gases ${ }^{[2]}$.

The increasing interest in biodegradable materials has motivated industrial and academic research to use biopolymers in applications where synthetic polymers or mineral fillers were traditionally used. As a result, intensive studies have been devoted to cellulose nanocrystals $(\mathrm{CN})$. The main characteristics that stimulate the use of $\mathrm{CN}$ as reinforcing agents in polymers include their large specific surface area (estimated at several hundred $\mathrm{m}^{2} \cdot \mathrm{g}^{-1}$ ), high elastic modulus $(150 \mathrm{GPa})$, low density (approximately $1.566 \mathrm{~g} / \mathrm{cm}^{3}$ ), biocompatibility, and biodegradability ${ }^{[3,4]}$.

CN-based nanocomposites generally exhibit significant improvements in thermal, mechanical, and barrier properties when compared to the neat polymer or conventional composites, even at low loading filler levels ${ }^{[5]}$. These outstanding properties were ascribed to a mechanical percolation, which results mainly from the strong interactions between $\mathrm{CN}$ through hydrogen bond forces phenomenon and the very short distances between the fillers (these distances begin to approach molecular dimensions $)^{[6,7]}$.

Due to its low cost, abundance, and availability, vegetable waste biomass can be better utilized, reducing production costs and disposal in the environment. It is clear that the manufacture of new high performance materials from vegetable waste biomass (e.g. soybean hulls) can provide technological, economic, and environmental benefits to the country.

Many polymeric matrices have been reinforced with $\mathrm{CN}$, resulting in nanocomposites that often showed improvements in thermomechanical properties, as is the case for polylactic acid (PLA) ${ }^{[8]}$, polycaprolactone (PCL) ${ }^{[9]}$, carboxymethylcellulose (CMC) $)^{[10]}$ and poly(vinyl alcohol) (PVA $)^{[11]}$. To the best of our knowledge in the literature, there are two studies in which the thermomechanical and barrier properties of the methylcellulose (MC) were improved by the addition of the montmorillonite nanoparticles ${ }^{[12]}$ and cellulose nanofibers ${ }^{[2]}$. However, there is no record in the literature of reinforcement of $\mathrm{MC}$ with $\mathrm{CN}$.

MC, a biodegradable polymer, is a modified type of cellulose that is the most abundant biopolymer in nature. MC is widely used in the pharmaceutical, food, agricultural, construction, paints, ceramics, detergents, adhesives, and cosmetics industries. This biopolymer is water soluble, has excellent film forming properties, and causes no toxic effects on the human body. Films made with this material have low permeability to oxygen and lipids, pose no threat to the environment, and are profitable. However, the limitations of these films include: weak thermo-mechanical properties and water sensitivity, and poor barrier properties ${ }^{[2]}$. In an attempt to maximize the potential use of MC films, in this study we developed unpublished nanocomposite films of MC reinforced with $\mathrm{CN}$, and evaluated their thermomechanical and barrier properties against light and water vapor. In the present

Corresponding author: Daniel Pasquini, Instituto de Química, Universidade Federal de Uberlândia - UFU, Campus Santa Mônica, Av. João Naves de Ávila, 2121, CEP 38400-902, Uberlândia, MG, Brazil, e-mail: pasquini@iqufu.ufu.br; danielpasquini2005@yahoo.com.br 
paper, the storage modulus $\left(E^{\prime}\right)$, loss tangent ( $\left.\tan \delta\right)$, water vapor permeability $(P w)$, light transmittance $(T r)$, and thermal stability $(T S)$ of the nanocomposites were measured at different filler loading levels.

\section{Experimental}

\section{Materials}

CN prepared according our previous work ${ }^{[4]}$, phosphorus pentoxide $\left(\mathrm{P}_{2} \mathrm{O}_{5}, 98.5 \%\right.$; Sigma-Aldrich), and methylcellulose powder $(\mathrm{MW}=40.000 ; \mathrm{GS}=1.75 \pm 0.01$ determined as described by Vieira et al. ${ }^{[13]}$; Sigma-Aldrich).

\section{Preparation of cellulose nanocrystals}

The CN were isolated from purified soy hulls and characterized in our previous work ${ }^{[4]}$. The obtained nanocrystals were denominated $\mathrm{WSH}_{30}$. The $\mathrm{WSH}_{30}$ were prepared by hydrolysis at $40^{\circ} \mathrm{C}$ for $30 \mathrm{~min}$ using $30 \mathrm{~mL}$ of $\mathrm{H}_{2} \mathrm{SO}_{4}(10.06 \mathrm{M})$ per gram of fiber.

\section{Preparation of MC/WSH30 nanocomposites}

Aqueous 1\%(w/v) MC solutions were mixed with aqueous suspension of $\mathrm{WSH}_{30}$ followed by ultrasonic treatment for $15 \mathrm{~min}$. The weight ratios of $\mathrm{WSH}_{30}$ to $\mathrm{MC}$ were 2:98 (2\%), 4:96 (4\%), 6:94 (6\%), 8:92 (8\%) and 10:90 (10\%). $\mathrm{MC} \mathrm{WSH}_{30}$ nanocomposite films and neat $\mathrm{MC}$ film were fabricated using a casting method at $35^{\circ} \mathrm{C}$ for $24 \mathrm{~h}$ in oven. The final mass of all the films was $0.7 \mathrm{~g}$ and their thickness ranged from 0.017 to $0.040 \mathrm{~mm}$.

\section{Characterizations and measurements}

\section{Dynamic Mechanical Thermoanalyses (DMTA)}

Dynamic mechanical properties of the nanocomposites films and neat MC film were evaluated using a TA Instruments DMA Q800 on rectangular films (ca. $20 \times 6.42$ $\times 0.04 \mathrm{~mm}$ ) in tensile mode with an oscillation frequency of $1 \mathrm{~Hz}$, a static force of $10 \mathrm{mN}$, an oscillation amplitude of $15.0 \mathrm{~mm}$, and an automatic tension setting of $125 \%$. Measurements were carried out with a heating rate of $3{ }^{\circ} \mathrm{C} /$ min and range of $25-250{ }^{\circ} \mathrm{C}$.

\section{Water Vapor Permeability (Pw)}

Water vapor permeability was measured by Payne's cup technique using $\mathrm{P}_{2} \mathrm{O}_{5}$ as a drying agent. To perform the analysis, permeation to water vapor was carried as described in the work of Morelli and Ruvolo Filho ${ }^{[14]}$, in which one can analyze the ability of each sample to permeate by its loss of mass, which was directly proportional to the loss of water flowing through the film in this case. The thicknesses of the films with $0,2,4,6,8$, and $10 \%$ load $\left(\mathrm{WSH}_{30}\right)$ were 3.124 , $2.972,2.591,2.108,1.905$, and $2.794 \mathrm{~mm}$, respectively. Two replicates of each sample were placed in a controlled environmental chamber with a constant temperature $(T)$ of $20.0 \pm 1.0^{\circ} \mathrm{C}$, pressure of vaporization of water $(D P v)$ of $17.54 \mathrm{mmHg}$, and $0 \%$ relative humidity.

\section{Light Transmittance (Tr)}

Light transmittance by the nanocomposite films and neat MC film was measured in a Shimadzu UV-vis spectrometer (model UV-250 1PC) at $25^{\circ} \mathrm{C}$ and correlated based on the film thicknesses using the Lambert-Beer's law. The experiments were carried out in the wavelength range of 200-800 nm with a $0.5 \mathrm{~nm}$ spectral bandwidth. The thickness of the films produced ranged from 0.025 to $0.035 \mathrm{~mm}$.

\section{Thermal Gravimetric Analysis (TGA)}

Thermal stabilities (TS) of the $\mathrm{WSH}_{30}$ and the nanocomposite films were evaluated using a Shimadzu DTG- $60 \mathrm{H}$ equipment. The analysis conditions were a nitrogen atmosphere with flow rate of $30 \mathrm{~mL} \cdot \mathrm{min}^{-1}$, heating rate of $10{ }^{\circ} \mathrm{C} \cdot \mathrm{min}^{-1}$, temperature range of 25 to $600{ }^{\circ} \mathrm{C}$, sample mass between 5 and $7 \mathrm{mg}$, and aluminum pans. The initial temperature of degradation $\left(T_{\text {ONSET }}\right)$ was defined as the intersection of the tangents drawn from the thermogravimetric curve, one before inflection caused by the degradation and the other from 5 mass $\%$ degradation after inflection.

\section{Results and Discussion}

\section{Preparation of cellulose nanocrystals}

In our previous work, the $\mathrm{WSH}_{30}$ were characterized according to their crystallinity index, morphology, and thermal stability. As we reported, $\mathrm{WSH}_{30}$ had a needleshaped characteristics, crystallinity of $73.5 \%$, initial degradation temperature of $\sim 200{ }^{\circ} \mathrm{C}$, average length (L) of $122.66 \pm 39.40 \mathrm{~nm}$, and a diameter (D) of 2.77 \pm 0.67 . The results of the morphological investigation using microscopy-based methods (Transmission Electron Microscopy and Atomic Force Microscopy) showed that the aspect ratio (L/D) for $\mathrm{WSH}_{30}$, ranging from about 24 up to 77 , with an average value of about $44^{[4]}$. This value was greater than 10 , which is considered the minimum value for good stress transfer from the matrix to the fibers for any significant reinforcement to occur ${ }^{[5]}$. Therefore, $\mathrm{WSH}_{30}$ have great potential to be used as reinforcing agents in nanocomposites.

\section{Dynamic Mechanical Thermoanalyses (DMTA)}

The Figures $1 \mathrm{a}$ and $1 \mathrm{~b}$ show the evolution of the tensile storage modulus $\left(E^{\prime}\right)$ and loss tangent $(\tan \delta)$, measured as a function of temperature, for the neat $\mathrm{MC}$ film and

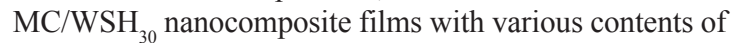
$\mathrm{WSH}_{30}$. The glass transition temperature $\left(T_{G}\right)$ of the samples was determined as the temperature at the maximum of the tan $\delta$ peak.

The value of $E$ ' is directly related to the ability of a material to withstand mechanical loads recoverable strain. The improvement in $E$ ' was found upon $\mathrm{CN}$ addition. The $E$ ' of the nanocomposites increased modestly between room temperature and $T_{G}$. The experimental values of $E$, at $25^{\circ} \mathrm{C}$ and $220^{\circ} \mathrm{C}$ are shown in Table 1 . For example, it increased from $3185.6 \mathrm{MPa}$ at $25^{\circ} \mathrm{C}$ for the neat polymer to $3857.2 \mathrm{MPa}$ for the nanocomposite with 8 wt $\% \mathrm{WSH}_{30}$, which corresponded to a $21.1 \%$ increase. The relative reinforcement was more significant above $T_{G}$ (in the rubbery plateau). For example, at $220^{\circ} \mathrm{C}$, the $E^{G}$, of the nanocomposite containing $8 \mathrm{wt} \% \mathrm{WSH}_{30}$ exhibited 


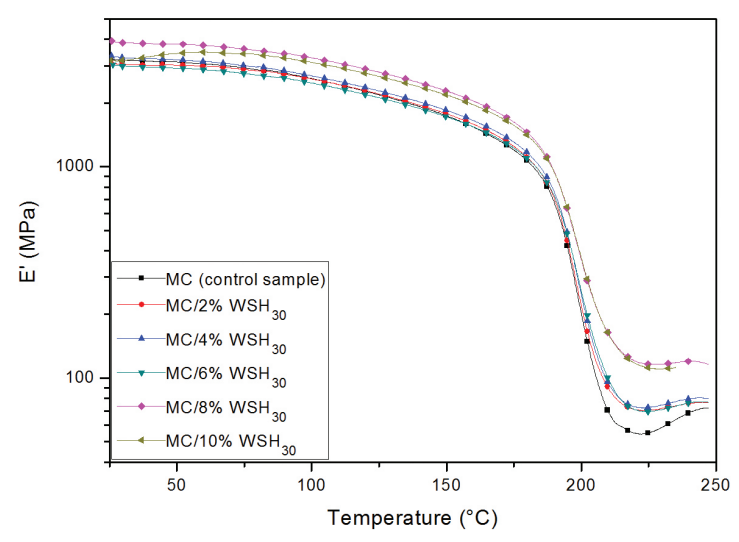

(a)

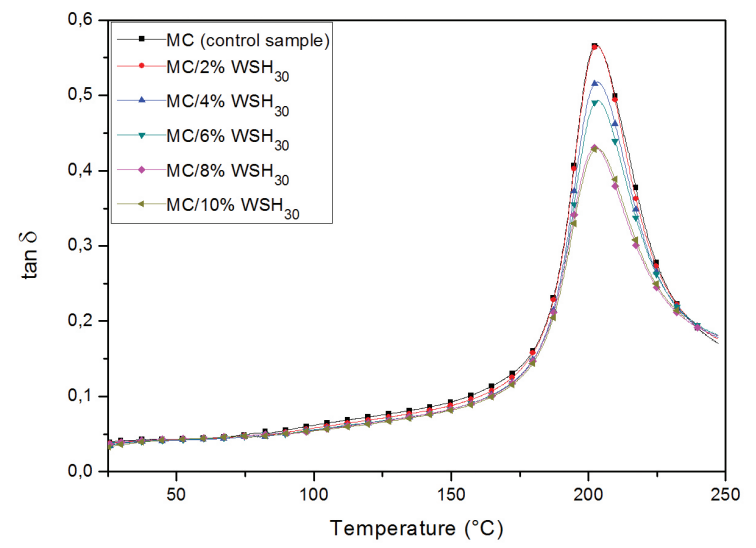

(b)

Figure 1. DMTA data obtained for the neat $\mathrm{MC}$ film and $\mathrm{MC} / \mathrm{WSH}_{30}$ nanocomposite films with 2, 4, 6, 8, and $10 \%$ filler. (a) Tensile storage modulus (E'), and (b) Loss factor $(\tan \delta$ ) of the films as a function of temperature.

Table 1. Main relaxation temperature $\left(T_{G}\right)$, tensile storage modulus $\left(E^{\prime}\right)$ estimated at 25 and $220{ }^{\circ} \mathrm{C}$, and $P w$ values (mean \pm standard deviation) for the neat $\mathrm{MC}$ film and $\mathrm{MC}_{\mathrm{G}} \mathrm{WSH}_{30}$ nanocomposite films at various contents of $\mathrm{WSH}_{30}$.

\begin{tabular}{ccccc}
\hline Filler content (\%) & $\boldsymbol{E}_{2{ }^{\circ}{ }^{\circ} \mathrm{C}}(\mathbf{M P a})$ & $\boldsymbol{E}_{220^{\circ} \mathrm{C}}(\mathbf{M P a})$ & $\boldsymbol{T}_{\boldsymbol{g}}\left({ }^{\circ} \mathbf{C}\right)$ & $\boldsymbol{P w}\left(\mathbf{1 0}^{-5} \cdot \mathbf{c m}^{2} \mathbf{. s}^{-1}\right)$ \\
\hline 0 & 3186 & 55 & 203 & $8.613 \pm 0.006$ \\
2 & 3041 & 71 & 203 & $7.961 \pm 0.054$ \\
4 & 3277 & 73 & 203 & $7.124 \pm 0.114$ \\
6 & 2991 & 71 & 204 & $6.006 \pm 0.024$ \\
8 & 3857 & 121 & 203 & $5.485 \pm 0.002$ \\
10 & 3176 & 117 & 204 & $7.492 \pm 0.014$ \\
\hline
\end{tabular}

a modulus of $120.6 \mathrm{MPa}$, which represents a $119.7 \%$ enhancement over that of the neat matrix (54.9 MPa).

The mechanical reinforcement observed for the nanocomposites above $T_{G}$ was most likely due to percolation. This means that the filler content is high enough for the formation of rigid $\mathrm{CN}$ networks, where stress transfer is facilitated by hydrogen-bonding between the $\mathrm{CN}^{[15]}$. This mechanism was shown to be responsible for the reinforcement of several polymeric matrices ${ }^{[16,17]}$. This hypothesis is supported by calculations obtained using a percolation model according with Siqueira et al. ${ }^{[18]}$. Taking into account the densities of $\mathrm{WSH}_{30}$ and $\mathrm{MC}, 1.57$ and 1.30 g. $\mathrm{cm}^{-3}$ respectively, and the aspect ratio of the nanoparticles (44), the percolation threshold calculated was $1.91 \%$ wt. This shows that percolation occurs in all nanocomposites developed in this study, since the smallest filler loading used was $2 \% \mathrm{wt}$.

It is well known that the large specific surface area, high modulus of elasticity, and the aspect ratio of $\mathrm{CN}$ play key roles in improving the mechanical properties of polymer/CN composites. Additionally, the hydroxyl groups present in the surface of the $\mathrm{CN}$ facilitate hydrogen bond interactions and adhesion between the matrix and filler, which may also lead to improvements in mechanical properties. These characteristics show the ability of $\mathrm{CN}$ to significantly reinforce a polymer matrix system at very low filler loadings. For example, the $E$ ' of nanocomposite could be increased to about $2200 \%$ higher than that of the bulk polymer matrix at only $4 \mathrm{wt} \%$ of the $\mathrm{CN}^{[15]}$.

The fact that the samples containing $10 \mathrm{wt} \%$ of $\mathrm{WSH}_{30}$ showed a slightly lower modulus than the sample containing $8 \mathrm{wt} \%$ may be explained by the aggregation of $\mathrm{CN}$ at higher concentrations. It was reported that for $\mathrm{MC}$ nanocomposite films reinforced with $10 \mathrm{wt} \%$ of montmorillonite nanoparticles ${ }^{[12]}$ at $30{ }^{\circ} \mathrm{C}$ (below the $T_{G}$ ), the $E$ ' value increased by $37.5 \%$ when compared to the neat matrix of MC. This increase was slightly higher than for $\mathrm{MC} / \mathrm{WSH}_{30}$ nanocomposite containing $8 \mathrm{wt} \%$ of filler ( $21.1 \%$ increase). However, at $220{ }^{\circ} \mathrm{C}$ (above the $T_{G}$ ), the $E$ ' value increased by about $72 \%$ for the nanocomposite film with $10 \mathrm{wt} \%$ of montmorilonite when compared to the neat matrix. This enhancement was smaller than the increase observed in our work at $220^{\circ} \mathrm{C}(119.7 \%$ for nanocomposite film with $8 \mathrm{wt} \%$ of $\mathrm{WSH}_{30}$ ).

For all the samples a modest increase of the storage modulus with temperature is observed in rubbery plateau region. However, for nanocomposites containing high nanofiller loading ( 8 and $10 \mathrm{wt} \%$ ) the modulus becomes roughly constant over a wide temperature region in rubbery plateau. While in the case of unfilled MC and low filler content nanocomposites $(2,4$ and $6 \mathrm{wt} \%)$, the increase of the rubbery modulus is known to depend on the degree of crystallinity of the material ${ }^{[19]}$.

The $\tan \delta$ is the mechanical loss factor, which is responsible for the damping properties of the material. This damping is associated with the phase equilibrium between the elastic and viscous phases in the material. The magnitude and area of the $\tan \delta$ peak decreases upon filler addition (Figure 1b). This was associated with the concomitant decrease in the $E$ ' drop, and this was responsible for the damping properties ${ }^{[20]}$. This behavior indicates that the filler $\left(\mathrm{WSH}_{30}\right)$ partially supports the 
tension applied on the composite, allowing only one part of this tension might deform the filler/matrix interface. In addition, the incorporation of fillers in the polymeric matrix lead to increased rigidity or restricted mobility of the polymer chains in the region of filler/matrix interface that can be attributed to molecular interactions between these components. Therefore, the relative peak height or area under of $\tan \delta$ peak are proportional to the volume of the constrained polymer chains and change systematically with amorphous content ${ }^{[19]}$.

In the experimental conditions used, DMTA revealed that the $T_{G}$ of the materials was not significantly influenced by the incorporation of the cellulose filler. As shown in Table 1 , the transition regions from a glassy state to rubbery state was approximately $203^{\circ} \mathrm{C}$, with a range less than $1{ }^{\circ} \mathrm{C}$, for all samples. The $T_{G}$ values were similar to previous values reported in the literature for the same polymer ${ }^{[2]}$.

The favorable interactions between the polymer matrix and cellulosic filler are confirmed by the relatively high reinforcing effect provided by the latter. Given the surface chemistry of the $\mathrm{CN}$, we speculate that hydrogen bond interactions between the hydroxyl groups on the surface of the $\mathrm{CN}$ with the polar sites of the methylcellulose matrix play a role.

\section{Water Vapor Permeability (Pw)}

The $P w$ values of the nanocomposites with different contents of $\mathrm{WSH}_{30}$ are shown in Table 1 .

The growth and metabolism of microorganisms require the presence of water in an available form. The most commonly used measurement to express the availability of water in food is water activity (aw). To reduce $a w$ in food, one can increase the concentration of solutes in the aqueous phase of the food, either by removing water or by adding solutes. A small reduction in $a w$ is often sufficient to have an effect in preserving food ${ }^{[11]}$. Given the necessity of reducing $a w$ in food packaged in polymeric films, it is very important to evaluate water transport through films produced for this use.
The results obtained for all nanocomposites showed good reduction in $P w$ when compared to the neat MC film. It was observed that the $P w$ was progressively reduced with increasing content of $\mathrm{WSH}_{30}$ up to $8 \%$. This is an indication that the nanoparticles were well dispersed and adhered in the polymeric MC matrix. The nanocomposite films with 2, 4, 6,8 , and $10 \%$ filler showed decreases in $P w$ by $7.57,17.29$, $30.27,36.32$, and $13.02 \%$, respectively. However, for us, the $P w$ at the $10 \%$ level was smaller due to agglomeration of $\mathrm{WSH}_{30}$, which occurred to a sufficient extent to provide channels or areas where the membrane permits greater $P w$.

The reduction of $P w$ in the nanocomposite $\mathrm{MC} / \mathrm{WSH}_{30}$ films can be explained by the physical barrier to the passage of water provided by $\mathrm{CN}$, i.e. the water must walk along the surface of $\mathrm{CN}$, but fails to pass through, thus leading to a slower diffusion processes and, hence, to a lower permeability ${ }^{[5]}$. The barrier properties are enhanced if the filler is less permeable and has a good dispersion into the matrix ${ }^{[21]}$. In the present study, the high crystallinity and the strong interactions between of the hydroxyls groups of the $\mathrm{CN}$, as well as the interactions of the $\mathrm{WSH}_{30}$ with the MC-based films components (mainly cellulose), may have enhanced water vapor barrier properties of the film $\mathrm{m}^{[2,23]}$.

The reductions in $P w$ observed for the nanocomposite films in this study were comparable to others reports. Khan et al. obtained $26 \%$ reduction in $P w$ with $1 \%$ cellulose nanofibers (CNF) in MC films when compared to the neat $\mathrm{MC}$ membrane ${ }^{[2]}$. Sánchez-García et al. obtained a largest reduction $(71 \%)$ in $P w$ with $3 \% \alpha$-cellulose microfibers (CNW) in Carrageenan films when compared to the neat Carrageenan film ${ }^{[24]}$.

\section{Light Transmittance (Tr)}

The results of the spectroscopy in the ultraviolet-visible (UV-VIS) region (200-800 nm) of the neat MC film and $\mathrm{MC} / \mathrm{WSH}_{30}$ nanocomposites with 2, 4, 6, 8, and $10 \%$ filler mass are shown in Figure 2. The films exhibited optical transmittances $(T r)$ very close and excellent in the spectrum of visible light (400-750 nm), which is an indication of good interfacial interation and compatibility of nanocomposites

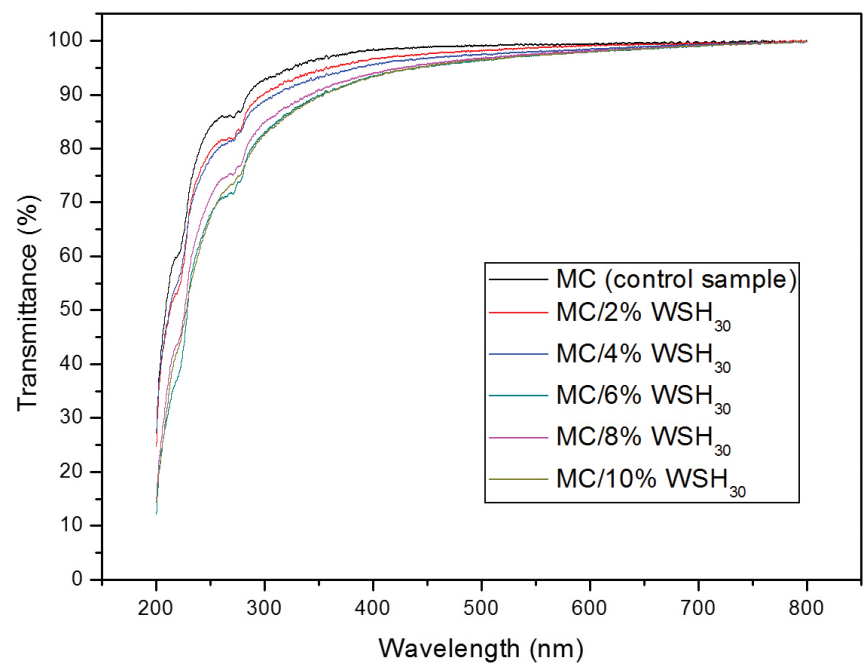

Figure 2. Optical transmittance $(\mathrm{Tr})$ versus wavelength $(200-800 \mathrm{~nm})$ of neat $\mathrm{MC}$ and $\mathrm{MC} / \mathrm{WSH}_{30}$ nanocomposite films with 2, 4, 6, 8, and $10 \%$ filler. 
and the polymer matrix. The nanometric characteristics of $\mathrm{WSH}_{30}$, with their ultrathin diameter of $2.77 \mathrm{~nm}$ and average length of $122.66 \mathrm{~nm}$, combined with a surface area of high hydrophilicity, substantially improved the intermolecular interactions through hydrogen bonding at the interfaces of the $\mathrm{WSH}_{30}$ and $\mathrm{MC}$ matrix ${ }^{[25,26]}$. However, it could not be determined whether there was uniform dispersion of the reinforcing material, since no specific technique was performed to determine this.

In the range of $300-450 \mathrm{~nm}$, we noted that there was a slight tendency of $\operatorname{Tr}$ to decrease (92.89-82.56\%) with increasing load ( $0-10 \%$ by mass) in the polymer matrix. However, no difference was greater than $10 \%$ of the $T r$ of the nanocomposites when compared to the $\operatorname{Tr}$ values of the neat MC film, thereby demonstrating good $T r$ of the nanocomposites in this range of wavelengths. Still, considering wavelengths in the $300-450 \mathrm{~nm}$ range, the $\operatorname{Tr}$ values for the nanocomposite with $6 \%$ of $\mathrm{WSH}_{30}$ were close to those of the nanocomposite with a $10 \%$ load. This probably occurred because the $\operatorname{Tr}$ experiment was a punctual test, and the region analyzed for the nanocomposite film $\mathrm{MC} / 6 \% \mathrm{WSH}_{30}$ could have been contaminated with some minimal amount of an impurity or there could be some small agglomeration of $\mathrm{WSH}_{30}$ in the nanocomposite occurring. In the final track of the spectrum $(450-800 \mathrm{~nm})$, the trend mentioned above is virtually nonexistent because all $\operatorname{Tr}$ were above $95 \%$. It is known that beyond the refractive index, which is inherent to each material, the porosity of the film surface also causes light scattering, so the excellent $T r$ of the films is at least one indication that they were minimally porous $^{[25,26]}$.

The nanocomposites produced in this work exhibited $\operatorname{Tr}$ values in the visible region larger than other similar systems, such as the nanocomposite prepared by Ayuk and his collaborators $[10 \mathrm{wt} \%$ microcrystalline cellulose nanocrystals (NCCMC) in cellulose acetate butyrate], which exhibited $\operatorname{Tr}$ values $50 \%$ and $65 \%$ at wavelengths of $600 \mathrm{~nm}$ and $800 \mathrm{~nm}$, respectively ${ }^{[27]}$. The $T r$ values of the $\mathrm{MC} / \mathrm{WSH}_{30}$ films were also higher than the nanocomposite produced by Tang and $\mathrm{Liu}^{[26]}(8.4 \mathrm{wt} \% \mathrm{CNF}$ from carpet dispersed PVA), which had $\operatorname{Tr}$ values less than $90 \%$ at $600 \mathrm{~nm}$.

\section{Thermal Gravimetric Analysis (TGA)}

The thermal degradation of the neat $\mathrm{MC}$ and $\mathrm{MC} /$ $\mathrm{WSH}_{30}$ nanocomposites as a function of $\mathrm{WSH}_{30}$ content is presented in Figure 3. A slight decrease in weight ( $\sim 1-5$ $\mathrm{wt} \%$ ) of $\mathrm{MC}$ and $\mathrm{MC}$ nanocomposites started below 120 ${ }^{\circ} \mathrm{C}$. The possible causes for the initial weight loss are probably due to moisture and the high water-retention capacity of $\mathrm{MC}^{[12]}$.

The main weight decrease of the neat MC and its nanocomposites occurred in the temperature range of $270-380{ }^{\circ} \mathrm{C}$, and was due to structure degradation of MC. Knowing that the decomposition of MC generally starts around $290{ }^{\circ} \mathrm{C}$, it is very important to note that the $\mathrm{CN}$ added to the MC matrix did not adversely affect its thermal stability (TS), in order to not hinder the processing of the nanocomposites in an industrial process, for example ${ }^{[28]}$.

The initial temperatures of degradation $\left(T_{\text {ONSET }}\right)$ of $\mathrm{WSH}_{30}$ was around $200{ }^{\circ} \mathrm{C}^{[4]}$, while the $T_{\text {ONSET }}$ of the nanocomposite films ranged from $260^{\circ} \mathrm{C}$ to $276^{\circ} \mathrm{C}$ and the $T_{\text {ONSET }}$ of the neat $\mathrm{MC}$ film was approximately $270^{\circ} \mathrm{C}$. The thermogravimetric analysis indicated retained the thermal stability of the nanocomposites. We can assume that $\mathrm{WSH}_{30}$ did not affect the $T_{\text {ONSET }}$ of MC films produced since the $\mathrm{WSH}_{30}$ are not only embedded in the polymer matrix, but also very involved for this matrix.

Beyond $500{ }^{\circ} \mathrm{C}$, thermograms were consistent for the appearance of carbonized residue in the curves of the nanocomposites. This was due to the sulfate groups on the surfaces of the $\mathrm{WSH}_{30}$, which act as flame retardants ${ }^{[28]}$. The carbonized residues from the nanocomposite films were $0.4-6.1 \%$ by weight.

The TS results obtained in this work are very important because it is not necessary any adjustment or modification of the processing of nanocomposites produced by further processing of MC.

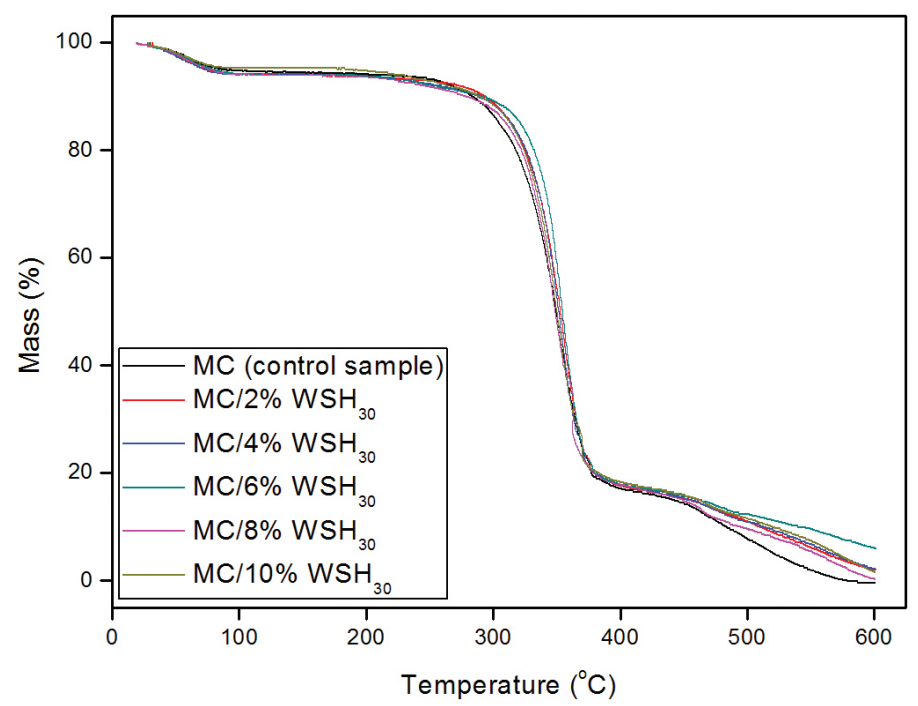

Figure 3. TG curves for films made from neat $\mathrm{MC}, \mathrm{MC} / 2 \% \mathrm{WSH}_{30}, \mathrm{MC}_{4} \% \mathrm{WSH}_{30}, \mathrm{MC} / 6 \% \mathrm{WSH}_{30}, \mathrm{MC} / 8 \% \mathrm{WSH}_{30}$, and $\mathrm{MC} / 10 \% \mathrm{WSH} 0^{\text {. }}$ 


\section{Conclusions}

The $\mathrm{WSH}_{30}$ provided a significant improvement $(119.7 \%)$ in the $E^{\prime}$ of the nanocomposites when only $8 \%$ of the filler had been incorporated into the MC. The reduction in $P w$ up to $36.32 \%$ when $8 \%$ loading was used, indicates that the $\mathrm{WSH}_{30}$ were well dispersed and adherent on the polymeric MC matrix. The reduction in permeability to water flow through the nanocomposite films provided by $\mathrm{WSH}_{30} \mathrm{CN}$ is a very important factor since these nanofillers reinforce the MC films and enhance their use in environments containing some moisture while still reducing water activity, which prevents, or at least slows, the growth of bacteria. These factors make such films reasonable alternatives that can expand the applications of commercial MC films for food packaging.

The effects of improving the mechanical and barrier properties of the films developed in this study suggests that there was the formation of a strong network of interactions that occur when the process allows for good dispersion and adhesion of the nanoparticles to the matrix, thus allowing more effective in forming strengths hydrogen bonds between the $\mathrm{WSH}_{30}$ and between nanoparticles and matrix.

The nanocomposites produced were quite translucent, showing $\operatorname{Tr}$ values in the visible range (400-750 $\mathrm{nm})$ very close to those of the neat MC film. The thermogravimetric analysis indicated that $T S$ was retained for the nanocomposites that we produced.

From the results shown in this study, it is clear that $\mathrm{CN}$ obtained from $\mathrm{WSH}_{30}$ have a great potential for use as reinforcing agents in nanocomposites. In this work, highperformance bionanocomposites for diverse applications were produced by adding $\mathrm{CN}$ to $\mathrm{MC}$ and then compared to the neat MC films.

\section{Acknowledgements}

Authors thanks CAPES, CNPq, FAPEMIG for financial support.

\section{References}

1. Simi, C. K. \& Abraham, T. E. - Colloid Polym. Sci., 288, p.297 (2010). http://dx.doi.org/10.1007/s00396-009-2151-8.

2. Khan, R. A.; Salmieri, S.; Dussault, D.; Uribe-Calderon, J.; Kamal, M. R.; Safrany, A. \& Lacroix, M. - J. Agric. Food Chem., 58, p.7878 (2010). http://dx.doi.org/10.1021/ jf1006853. PMid:20545366

3. Dufresne, A. - Compos. Interfaces., 10, p.369 (2003). http:// dx.doi.org/10.1163/156855403771953641.

4. Flauzino Neto, W. P.; Silvério, H. A.; Dantas, N. O. \& Pasquini, D. - Ind. Crops Prod., 42, p.480 (2013). http://dx.doi. org/10.1016/j.indcrop.2012.06.041.

5. Azeredo, H. M. C.; Mattoso, L. H. C.; Wood, D.; Williams, T. G.; Avena-Bustillos, R. J. \& McHugh, T. H. - J. Food Sci., 74, p.N31 (2009). http://dx.doi.org/10.1111/j.17503841.2009.01186.x. PMid:19646052

6. Favier, V.; Canova, G. R.; Cavaillé, J. Y.; Chanzy, H.; Dufresne, A. \& Gauthier, G. - Polym. Adv. Technol., 6, p.351 (1995a). http://dx.doi.org/10.1002/pat.1995.220060514.

7. Favier, V.; Chanzy, H. \& Cavaillé, J. Y. - Macromolecules., 28, p.6365 (1995b). http://dx.doi.org/10.1021/ma00122a053.
8. Lin, N.; Chen, G. J.; Huang, J.; Dufresne, A. \& Chang, P. R. - J. Appl. Polym. Sci., 113, p.3417 (2009). http://dx.doi. org/10.1002/app.30308.

9. Siqueira, G.; Bras, J. \& Dufresne, A. - Biomacromolecules., 10, p.425 (2009). http://dx.doi.org/10.1021/bm801193d. PMid: 19113881

10. Flauzino Neto, W. P.; Silvério, H. A.; Vieira, J. G.; Alves, H. C. S.; Pasquini, D.; Assunção, R. M. N. \& Dantas, N. O. - Macromol. Symp., 319, p.93 (2012). http://dx.doi. org/10.1002/masy.201100194.

11. Silvério, H. A.; Flauzino Neto, W. P. \& Pasquini, D. - J. Nanomater., 2013, p.1 (2013). http://dx.doi. org/10.1155/2013/289641.

12. Rimdusit, S.; Jingjid, S.; Damrongsakkul, S.; Tiptipakorn, S. \& Takeichi, T. - Carbohydr. Polym., 72, p.444 (2008). http:// dx.doi.org/10.1016/j.carbpol.2007.09.007.

13. Vieira, R. G. P.; Rodrigues Filho, G.; Assunção, R. M. N.; Meireles, C. S.; Vieira, J. G. \& Oliveira, G. S. - Carbohydr. Polym., 67, p.182 (2007). http://dx.doi.org/10.1016/j. carbpol.2006.05.007.

14. Morelli, F. C. \& Ruvolo Filho, A. - Polímeros., 20, p.121 (2010). http://dx.doi.org/10.1590/S0104-14282010005000014.

15. Tang, L. \& Weder, C. - Appl. Mater. \& Inter., 2, p.1073 (2010). http://dx.doi.org/10.1021/am900830h.

16. Capadona, J. R.; Shanmuganathan, K.; Tyler, D. J.; Rowan, S. J. \& Weder, C. - Science., 319, p.1370 (2008). http://dx.doi. org/10.1126/science.1153307. PMid:18323449

17. Azizi Samir, M. A.; Alloin, F. \& Dufresne, A. - Biomacromolecules., 6, p.612 (2005). http://dx.doi. org/10.1021/bm0493685. PMid:15762621

18. Siqueira, G.; Bras, J. \& Dufresne, A. - Polymers., 2, p. 728 (2010). http://dx.doi.org/10.3390/polym2040728.

19. Bindu, P. \& Thomas, S. - J. Phys. Chem. B., 117, p.12632 (2013). http://dx.doi.org/10.1021/jp4039489. PMid:24090199

20. Pasquini, D.; Teixeira, E. M.; Curvelo, A. A. S.; Belgacem, M. N. \& Dufresne, A. - Ind. Crops Prod., 32, p.486 (2010). http://dx.doi.org/10.1016/j.indcrop.2010.06.022.

21. Lagaron, J. M.; Catalá, R. \& Gavara, R. - J. Mater. Sci. Technol., 20, p.1 (2004). http://dx.doi. org/10.1179/026708304225010442.

22. Azeredo, H. M.; Mattoso, L. H.; Avena-Bustillos, R. J. A.; Filho, G. C.; Munford, M. L.; Wood, D. \& Mchugh, T. H. - J. Food Sci., 75, p.N1 (2010). http://dx.doi.org/10.1111/j.17503841.2009.01386.x.

23. Paralikar, S. A.; Simonsen, J. \& Lombardi, J. - J. Membr. Sci., 320, p.248 (2008). http://dx.doi.org/10.1016/j. memsci.2008.04.009.

24. Sánchez-García, M. D.; Hilliou, L. \& Lagarón, J. M. - J. Agric. Food Chem., 58, p.12847 (2010). http://dx.doi.org/10.1021/ jf102764e. PMid:21073192

25. Moon, R. J.; Martini, A.; Nairn, J.; Simonsen, J. \& Youngblood, J. - Chem. Soc. Rev., 40, p.3941 (2011). http://dx.doi. org/10.1039/c0cs00108b. PMid:21566801

26. Tang, C. \& Liu, H. - Compos., Part A Appl. Sci. Manuf., 39, p.1638 (2008). http://dx.doi.org/10.1016/j. compositesa.2008.07.005.

27. Etang Ayuk, J.; Mathew, A. P. \& Oksman, K. - J. Appl. Polym. Sci., 114, p.2723 (2009). http://dx.doi.org/10.1002/app.30583.

28. Roman, M. \& Winter, W. T. - Biomacromolecules., 5, p.1671 (2004). http://dx.doi.org/10.1021/bm034519+. PMid: 15360274

Received: Feb. 20, 2014 Accepted: July 10, 2014 